\title{
Impaired Myogenic Tone in Isolated Cerebral and Coronary Resistance Arteries from the Goto-Kakizaki Rat Model of Type 2 Diabetes
}

\author{
H. Kold-Petersen ${ }^{b} \quad$ E. Brøndum ${ }^{a}$ b $\quad$ H. Nilsson ${ }^{b} \quad$ A. Flyvbjerg ${ }^{c} \quad$ C. Aalkjaer ${ }^{b}$ \\ ${ }^{a}$ NeuroSearch A/S, Ballerup, and ${ }^{b}$ The Water and Salt Research Center, Institute of Biomedicine, Faculty of Health \\ Sciences, Aarhus University, and ' Department of Endocrinology and Internal Medicine, Aarhus University Hospital \\ and the Medical Research Laboratories, Institute of Clinical Medicine, Faculty of Health Sciences, Aarhus, Denmark
}

\section{Key Words}

Myogenic tone - Intracellular calcium • Resistance arteries •

Endothelium • Type 2 diabetes

\begin{abstract}
Aim: Type 2 diabetes is associated with stroke and cardiac dysfunction. We therefore investigated isolated middle cerebral arteries and coronary septal arteries from the diabetic Goto-Kakizaki (GK) rat model of nonobese type 2 diabetes. Methods: Myogenic tone and agonist-induced responses were investigated under isobaric conditions with simultaneous recording of $\left[\mathrm{Ca}^{2+}\right]_{\mathrm{i}}$. Rho-kinase and NO pathways were investigated using specific pharmacological tools. Results: Arteries from GK rats developed less tone at pressures from 20 to $100 \mathrm{~mm} \mathrm{Hg}$ than arteries from control Wistar (CW) rats while $\left[\mathrm{Ca}^{2+}\right]_{\mathrm{i}}$ was similar. Blocking the Rho-kinase pathway decreased the pressure-induced development of tone and after blockade no difference in myogenic tone between arteries from GK and CW rats was seen. Cerebral arteries had similar tone to a maximal concentration of U46619 (GK: 35.5 $\pm 2 \%$ vs. CW: $31.6 \pm 5 \%$ ), while coronary arteries from GK rats developed less tone than arteries from $\mathrm{CW}$ rats $(12 \pm 3$ vs. $26.1 \pm 3 \%$ ). Endothelium-dependent vasodilation to A23187 (cerebral) and to acetylcholine (coronary) was not different between arteries from GK and CW rats. Conclusion:
\end{abstract}

\section{KARGER}

Fax +4161306 1234

E-Mail karger@karger.ch

www.karger.com
(C) 2012 S. Karger AG, Basel

$1018-1172 / 12 / 0493-0267 \$ 38.00 / 0$

Accessible online at:

www.karger.com/jvr
Our data suggest that in resistance arteries from the brain and the heart of GK rats the myogenic tone is decreased due to impaired calcium sensitivity likely due to a defective Rhokinase pathway.

Copyright $\odot 2012$ S. Karger AG, Basel

\section{Introduction}

Type 2 diabetes (T2D) is associated with the development of diabetic angiopathy, presenting with microvascular (retinopathy, nephropathy and peripheral neuropathy) and macrovascular (stroke, cardiac dysfunction and peripheral ischemic leg disease) complications [1-3]. The nature of these vascular abnormalities is not fully understood, but it is believed that the vascular abnormalities associated with diabetes partly arise from a disruption in the local control of flow in the resistance arteries $[4,5]$. However, it is uncertain whether the same cellular abnormalities lead to the same vascular abnormalities in different vascular beds. The resistance arteries are crucial in controlling that local blood perfusion meets the tissue requirements and the control is exercised by changing the flow in the arteries by contraction of the vascular smooth muscle cells. A change in the contractile state of the vascular smooth muscle cells alters the diameter of the blood 
vessels and, as resistance is related to the fourth power of the vessel radius, even small changes in internal diameter cause major changes in flow.

A specific type of smooth muscle contraction dominant in the microvasculature is the pressure-induced contraction, also known as the myogenic response [6]. This response plays a central role in the autoregulation of blood flow and control of capillary pressure [7-9] and recent studies have shown that both the structure [10] and myogenic response [11] are altered in resistance arteries from patients with diabetes. The myogenic response is the initial response to a given change in transmural pressure across the arterial wall. This change is followed by a new level of myogenic tone. [12]. Myogenic tone is considered the backbone upon which vasodilators, such as nitric oxide (NO) and calcium channel blockers, act to lower resistance [6].

The present study was undertaken to compare two vascular beds with significant impact on morbidity and mortality in T2D, namely the heart and the brain. In particular, we have investigated the hypothesis that the myogenic tone and the sensitivity of the contractile apparatus to intracellular calcium are abnormal in a rat model of nonobese T2D, the Goto-Kakizaki (GK) rat, and that the arteries from these rats express endothelial dysfunction.

Accordingly, we investigated the vascular response and myogenic tone in isolated cerebral and coronary septal arteries from GK rats and compared those to the responses of similar arteries from control Wistar (CW) rats. We particularly wanted to address the sensitivity of the contractile apparatus to $\mathrm{Ca}^{2+}$ and the potential role of Rho-kinase by using the pharmacologic tools Y-27632 and fasudil, which both have an $\mathrm{IC}_{50}$ of approximately $1 \mu \mathrm{M}[13-15]$.

The GK rat model is derived by repetitive inbreeding of glucose-intolerant CW rats [16], and the GK rat strain presents with glucose intolerance, hyperglycemia, hypoinsulinemia and in some reports mild hypertension. These abnormalities develop spontaneously as early as 4 weeks after birth [17-21], and can to some degree be reversed by treatment with metformine [17]. We chose to use animals at a late stage of diabetes, i.e. 22 weeks, as this would provide a situation where the diabetes would be well manifested and the pathological abnormalities of the arteries would most likely be expressed [17, 22].

Our data suggest an impaired myogenic tone of both the cerebral and coronary resistance arteries and an attenuation of the calcium sensitivity of the contractile apparatus in both vascular beds, probably due to an attenuation of the Rho-kinase-dependent pathway.

\section{Methods}

Twenty-six male GK and CW rats (Wistar-HannoverGALLAS) were used. All rats were obtained from Taconic Europe (Ry, Denmark) and had free access to drinking water and standard rat chow (Altromin 1324; Lage, Germany). At the age of 16 weeks a subset of rats was weighed and nonfasting blood glucose determined (Precision Xtra ${ }^{\mathrm{TM}}$; Abbott Laboratories Medisense Products, Bedford, Mass., USA) along with blood pressure measured by tail plethysmography. These measures were repeated at 22 weeks. Experiments with isolated arteries were conducted at the age of 22 weeks when the rats were anesthetized with gaseous carbon dioxide and decapitated before the heart and brain were removed and the hearts weighed. All animal experiments were conducted according to the Danish ethical guidelines.

\section{Isobaric Diameter Measurement of Resistance Arteries}

Myogenic tone in coronary septal arteries and middle cerebral arteries was examined in a pressure myograph system (DMT, Aarhus, Denmark) that allowed us to control the transmural pressure.

After decapitation, the brain and the heart were carefully removed and placed in a physiological salt solution (PSS; for composition see below) at $4^{\circ} \mathrm{C}$. After placing the brain in a Petri dish, the proximal part of the middle cerebral artery was dissected free of surrounding connective tissue and a $3-\mathrm{mm}$ branch-free segment between the circle of Willis and the point of bifurcation was harvested. When dissecting the heart, the right ventricular cavity was exposed and the coronary septal artery was carefully dissected free from the cardiac tissue. The 3 most distal millimeters of the coronary septal artery before the point of bifurcation were used. The arterial segments were then moved to the pressure myograph bath which was filled with oxygenated PSS. Care was taken to select segments without branches. The vessels were cannulated at both ends with oxygenated PSS-filled glass micropipettes. The distal pipette was occluded allowing experiments to be made under conditions of no flow. The proximal pipette was connected to a pressure regulator (Mini Pressure Regulator; DMT). The arteries were then emptied of residual blood by gentle flushing through the lumen and finally mounted on the proximal pipette and tied with a single strand of braided 4-0 silk suture. Only vessels without leaks were used for further experiments.

PSS was continuously bubbled with $5 \% \mathrm{CO}_{2}$ in air to maintain $\mathrm{pH} 7.4$, and the temperature was kept at $37^{\circ} \mathrm{C}$. The myograph was placed on the stage of an inverted microscope (Leica, Wetzlar, Germany) equipped with a CCD camera (SONY, model XC-75CE; Tokyo, Japan) and the external diameter of the vessels was measured from the video images of the preparation during continuous transillumination with red light (wavelength $>600 \mathrm{~nm}$ ).

\section{Measurement of $\left[\mathrm{Ca}^{2+}\right]_{i}$ in Resistance Arteries}

After mounting, the arteries were loaded with $5 \mu \mathrm{M}$ fura-2 acetoxymethyl ester for $1 \mathrm{~h}$ at $37^{\circ} \mathrm{C}$. Fura-2 acetoxymethyl ester $(50 \mu \mathrm{g})$ was dissolved in a $4-\mu \mathrm{l}$ load mix $(10 \mathrm{ml}$ DMSO with 0.2 $\mathrm{ml}$ Cremophor EL and $40 \mathrm{mg}$ Pluronic F 127) and the final DMSO concentration in the bath was $0.04 \%$. After loading, the vessels were washed with PSS and rested for $15 \mathrm{~min}$ at $20 \mathrm{~mm} \mathrm{Hg}$. Fluorescence from the preparation was measured using epifluorescence. The preparation was excited by light alternating between two different wavelengths ( 340 and $380 \mathrm{~nm}$ ), generated by feeding 
the light from a 75W Xenon lamp into two separate monochromators by a computer-controlled optical chopper (DeltaScan Illuminator; PTI, UK). The transmitted light and fluorescence emission were collected by a $20 \times$ objective (NA 0.50; Leica) and directed to a microscope photometer (model D-104B/C; PTI) via a dichroic mirror $(>400 \mathrm{~nm})$. In the photometer, the transmitted red light was redirected to the video camera by a dichroic mirror $(>580$ $\mathrm{nm}$ ) for measurements of external vessel diameters, and the fluorescent light passed through a 520-560-nm bandpass filter to a photomultiplier tube (PMT, model 710; PTI). All signals were digitized at $10 \mathrm{~Hz}$ and stored on computer.

The fluorescence ratio was calculated as the ratio of emitted light in response to excitation at 340 and $380 \mathrm{~nm}(340 / 380 \mathrm{~nm})$, and taken as an estimate of $\left[\mathrm{Ca}^{2+}\right]_{i}$.

At the end of each experiment at a pressure of $100 \mathrm{~mm} \mathrm{Hg}, 40$ $\mu \mathrm{M}$ of ionomycin in a $\mathrm{Ca}^{2+}$-free solution was added to the bath. After obtaining the lowest fluorescence ratio $\left(\mathrm{R}_{\min }\right), 2.5 \mathrm{mM} \mathrm{Ca}^{2+}$ was added in order to obtain the highest fluorescence ratio $\left(\mathrm{R}_{\max }\right)$. To quench the dye, allowing the background signal to be obtained, $20 \mu \mathrm{M}$ of manganese chloride was added to the bath. The background signal was subtracted from all fluorescence measurements. No differences were seen between the two groups of rats in either the cerebral arteries or the coronary septal arteries with respect to $R_{\min }, R_{\max }$ or the background signal.

\section{Experimental Protocol for Resistance Cerebral Arteries}

In all arteries a pressure-diameter curve was obtained by increasing the pressure from 20 to $100 \mathrm{~mm} \mathrm{Hg}$ in $20-\mathrm{mm} \mathrm{Hg}$ increments. The arteries were maintained at each pressure level for $5 \mathrm{~min}$, allowing the vessel to reach a steady-state diameter. One group of arteries was then incubated with $100 \mu \mathrm{M} \mathrm{N}$-nitro-L-arginine (L-NAME) for $30 \mathrm{~min}$ at a pressure of $20 \mathrm{~mm} \mathrm{Hg}$ before another pressure-diameter curve was obtained. The pressure was again set to $20 \mathrm{~mm} \mathrm{Hg}$ and still in the presence of L-NAME the artery was incubated for 15 min with $3 \mu \mathrm{M}$ Y-27632 or fasudil before a third pressure-diameter curve was obtained.

In another group of arteries the pressure was set to $60 \mathrm{~mm} \mathrm{Hg}$ for $15 \mathrm{~min}$, after the pressure-diameter curve had been obtained, before a cumulative concentration-response curve to the thromboxane analog $\mathrm{U} 46619(0.01,0.1,0.3 \mu \mathrm{M})$ or $\operatorname{AVP}(0.3,1,3,10 \mu \mathrm{M})$ was obtained. After washout the vessels were incubated for $15 \mathrm{~min}$ with $3 \mu \mathrm{M}$ Y-27632 at $20 \mathrm{~mm} \mathrm{Hg}$ before a second pressure-diameter curve was obtained. Vessels were then washed and pressure set to $60 \mathrm{~mm} \mathrm{Hg}$ before substituting PSS with $125 \mathrm{mM} \mathrm{K}^{+}$-PSS (see 'Solutions and Chemicals') for depolarization of the artery. A third group of arteries was preconstricted with cumulative concentrations of U46619 at $60 \mathrm{~mm} \mathrm{Hg}$ before being exposed to either increasing concentrations of the endothelium-specific calcium ionophore A23187 $(0.1,1,10 \mu \mathrm{M})$ or a single high concentration $(10 \mu \mathrm{M})$. In 4 experiments cerebral arteries from GK and CW rats were incubated with $100 \mu \mathrm{M} \mathrm{L}-\mathrm{NAME}$ before the application of A23187. At the end of each experiment a pressure-diameter curve was obtained in $\mathrm{Ca}^{2+}$-free PSS containing $5 \mathrm{mM}$ ethylene glycolbis(2-aminoethylether)-N,N, $\mathrm{N}^{\prime}, \mathrm{N}^{\prime}$-tetraacetic acid to obtain the passive diameter.

\section{Experimental Protocol for Coronary Resistance Arteries}

In all arteries a pressure-diameter curve was obtained as described above. One group of arteries was then incubated with 100 $\mu \mathrm{M} \mathrm{L}-\mathrm{NAME}$ for $30 \mathrm{~min}$ at a pressure of $20 \mathrm{~mm} \mathrm{Hg}$ before the pressure-diameter curve was repeated. The pressure was again set to $20 \mathrm{~mm} \mathrm{Hg}$ and the arteries were incubated with $3 \mu \mathrm{M}$ fasudil for $15 \mathrm{~min}$ before a third pressure-diameter curve was obtained. In another group of arteries the pressure was set to $60 \mathrm{~mm} \mathrm{Hg}$ and after 15 min 3 cumulative concentrations of U46619 were applied $(0.01,0.1,0.3 \mu \mathrm{M})$ creating a concentration-response curve. After washout the pressure was set to $20 \mathrm{~mm} \mathrm{Hg}$ and the artery was incubated with $3 \mu \mathrm{M}$ Y-27632 for $15 \mathrm{~min}$ before a pressure-diameter curve and a concentration-response curve to U46619 at $60 \mathrm{~mm}$ $\mathrm{Hg}$ were obtained. In a third group of arteries pressure was set to $60 \mathrm{~mm} \mathrm{Hg}$ and arteries preconstricted with $30 \mu \mathrm{M} \mathrm{U} 46619$ before a cumulative concentration-response curve to $\mathrm{ACh}$ was obtained $(0.1,0.3,1,10 \mu \mathrm{M})$. ACh was then washed out and the artery was incubated with $100 \mu \mathrm{M}$ L-NAME for $30 \mathrm{~min}$ before a concentration-response curve to ACh was obtained. ACh was again washed out and the artery exposed to $30 \mathrm{mM} \mathrm{K}^{+}$-PSS and $125 \mathrm{mM} \mathrm{K}^{+}$-PSS before and after incubation with $10 \mu \mathrm{M}$ nifedipine. At the end of each experiment a pressure-diameter curve was obtained under $\mathrm{Ca}^{2+}$-free conditions as described for cerebral arteries.

\section{Calculations}

As response to increasing pressure (myogenic response) was assessed at steady state, results are presented as myogenic tone. Both myogenic tone and agonist-induced tone are expressed as relative diameter, which is the diameter as a percentage of the diameter in $\mathrm{Ca}^{2+}$-free PSS $\left[1-\left(\mathrm{D}_{\mathrm{PSS}} / \mathrm{D}_{\mathrm{Ca} \text {-free }}\right) \times 100 \%\right.$, where $\mathrm{D}$ is the diameter at the same pressures]. In the dilation curves $0 \%$ represents preconstricted diameter to U46619 and 100\% represents the diameter in $\mathrm{Ca}^{2+}$-free solution.

\section{Solutions and Chemicals}

The composition of PSS was (in $\mathrm{mM}$ ) $119 \mathrm{NaCl}, 4.7 \mathrm{KCl}, 1.18$ $\mathrm{KH}_{2} \mathrm{PO}_{4}, 1.17 \mathrm{MgSO}_{4}, 25 \mathrm{NaHCO}_{3}, 1.6 \mathrm{CaCl}_{2}, 0.026$ EDTA and 5.5 glucose. $\mathrm{K}^{+}$-PSS was PSS in which $\mathrm{NaCl}$ was substituted by an equimolar concentration of $\mathrm{KCl}$ to reach $30 \mathrm{mM}$ or $125 \mathrm{mM} \mathrm{K}^{+}$PSS. The $\mathrm{Ca}^{2+}$-free solution was PSS with no $\mathrm{CaCl}_{2}$ and $5 \mathrm{~mm}$ EGTA. All chemicals were bought from Sigma Chemical (St. Louis, Mo., USA).

\section{Statistics}

All data are presented as mean \pm SEM with a significance level of $\mathrm{p}<0.05 ; \mathrm{n}$ is the number of animals. Animal characteristics and maximal relaxation were compared by Student's t test. Differences between groups to increasing pressures were tested by 2-way ANOVA for repeated measures with Bonferroni's posttest. Effect of pharmacological treatment was tested by 2 -way ANOVA for repeated measures (within groups). Statistical analyses were made with GraphPad Prism 4.02 (GraphPad Software, La Jolla, Calif., USA).

\section{Results}

\section{Animal Parameters}

The blood glucose levels were significantly higher in GK rats than in CW rats both at 16 and 22 weeks of age. The GK rats had a lower body weight at 16 and 22 weeks of age than the CW rats. At the age of 22 weeks, the hearts 
Table 1. Characteristics of the animals of all experimental groups

\begin{tabular}{|c|c|c|c|c|}
\hline & \multicolumn{2}{|l|}{16 weeks } & \multicolumn{2}{|l|}{22 weeks } \\
\hline & $\mathrm{CW}$ rats & GK rats & $\mathrm{CW}$ rats & GK rats \\
\hline Blood glucose, $10^{-3} \mathrm{M}$ & $5.3 \pm 0.1$ & $10.6 \pm 0.4^{*}$ & $5.7 \pm 0.2$ & $9.2 \pm 1.9^{*}$ \\
\hline Body weight, g & $375 \pm 4$ & $351 \pm 5^{*}$ & $452 \pm 13$ & $419 \pm 7^{*}$ \\
\hline Heart weight, $g$ & NA & NA & $1.09 \pm 0.04$ & $1.39 \pm 0.06^{*}$ \\
\hline Heart weight/body weight & NA & NA & $\begin{aligned} 2.4 & \times 10^{-3} \pm \\
8 & \times 10^{-5}\end{aligned}$ & $\begin{array}{r}3.3 \times 10^{-3} \pm \\
11 \times 10^{-5 *}\end{array}$ \\
\hline Blood pressure, mm Hg & $116 \pm 1$ & $118 \pm 1$ & $122 \pm 5$ & $127 \pm 4$ \\
\hline
\end{tabular}

Values are mean \pm SEM and were analyzed by Student's $t$ test; $n=8-20$ rats per group. ${ }^{*} \mathrm{p}<0.05$, GK rats vs. age-matched CW rats. NA = Not assessed.

of the GK rats were larger than the hearts of the CW rats both in absolute terms and in relation to body weight despite a similar blood pressure at the respective ages (table 1).

\section{Isobaric Diameter of Middle Cerebral Arteries}

The passive diameter of the cerebral arteries in $\mathrm{Ca}^{2+}$ free conditions (at $100 \mathrm{~mm} \mathrm{Hg}$ ) was similar in the two groups: $215 \pm 10$ versus $199 \pm 8 \mu \mathrm{m}$ (nonsignificant, NS; $\mathrm{n}=20,26) \mathrm{GK}$ and CW rats, respectively. Under control conditions arteries from GK rats developed significantly less tone at all intraluminal pressures $(20,40,60,80$ and $100 \mathrm{~mm} \mathrm{Hg}$ ) than CW arteries ( $\mathrm{p}<0.05 ; \mathrm{n}=10,16$; fig. 1a, 2a). Incubation with L-NAME did not affect myogenic tone (fig. 3a) or $\left[\mathrm{Ca}^{2+}\right]_{\mathrm{i}}$ (not shown) indicating that the mechanisms responsible for the difference in tone were NO independent. Incubation with the Rho-kinase inhibitor fasudil substantially reduced the myogenic tone in CW arteries while no effect was seen in GK arteries, and in the presence of Rho-kinase inhibition no difference was seen between the arteries from GK and CW rats (fig. 3b). Using Y-27632 - another Rho-kinase inhibitor - also eliminated the difference between GK and CW arteries (data not shown).

Activation with increasing concentrations of the thromboxane analog U46619 revealed that cerebral arteries from GK and CW rats developed the same tone at the maximal concentration used, i.e. $32 \pm 4$ versus $38 \pm$ $2 \%(\mathrm{NS} ; \mathrm{n}=8,10) \mathrm{GK}$ and CW rats, respectively (fig. 4a). Incubation with Y-27632 had little effect on tone in GK arteries but substantially decreased maximal tone in CW arteries and in the presence of Y-27632 the tone at the maximal concentration of U46619 was significantly larger in arteries from GK than in arteries from CW rats.
Also, during stimulation with $10 \mu \mathrm{M}$ AVP (which is a supramaximal concentration) arteries from $\mathrm{GK}$ and $\mathrm{CW}$ rats had the same tone, i.e. $38 \pm 5$ versus $34 \pm 5 \%$ (NS; $\mathrm{n}=3,3) \mathrm{GK}$ and CW rats, respectively, which was also the case when the arteries were depolarized by $125 \mathrm{mM} \mathrm{K}^{+}$PSS: $43 \pm 3$ versus $40 \pm 3 \%(\mathrm{NS} ; \mathrm{n}=5,5) \mathrm{GK}$ and $\mathrm{CW}$ rats, respectively.

To test the endothelial function, the cerebral arteries were preconstricted with $0.3 \mu \mathrm{M}$ U46619 before exposing them to either increasing concentrations of the calcium ionophore A23187 (fig. 5a) or a single high concentration of $10 \mu \mathrm{M}$ A23187 (fig. 5b). A stepwise increase in concentrations revealed a concentration dependency of the response, with a maximal relaxation of $61 \pm 10$ and $74 \pm$ $4 \%(N S ; n=3,3)$ at the highest concentration of A23187 $(10 \mu \mathrm{M})$, in GK and CW rats, respectively (fig. 5a). A single high concentration resulted in an almost complete dilation of arteries from both groups, i.e. $89.8 \pm 4.0$ versus $91.4 \pm 3.0 \%(\mathrm{NS} ; \mathrm{n}=6,9)$, in GK and CW rats, respectively. Following incubation with L-NAME the relaxation to A23187 was significantly reduced to $42 \pm 11$ and $48 \pm$ $7 \%(\mathrm{p}<0.05 ; \mathrm{n}=3,3)$, in GK and CW rats, respectively (fig. 5b).

Despite the observation that arteries from GK rats had less myogenic tone compared to arteries from $\mathrm{CW}$ rats, there were no differences in $\left[\mathrm{Ca}^{2+}\right]_{\mathrm{i}}$ between the two groups throughout the entire pressure range (fig. 1a, 6a). After incubation with fasudil we still observed the same levels of $\left[\mathrm{Ca}^{2+}\right]_{\mathrm{i}}$ in the two groups throughout the entire pressure range (fig. 6a). Furthermore, in the absence of extracellular $\mathrm{Ca}^{2+}$ there was no difference in $\left[\mathrm{Ca}^{2+}\right]_{\mathrm{i}}$ between arteries from the two groups of rats, i.e. fluorescence ratio $1.1 \pm 0.2$ versus $1.1 \pm 0.1$ at $60 \mathrm{~mm} \mathrm{Hg}$ (NS; $\mathrm{n}=9,10)$, in GK and CW rats, respectively. 
Fig. 1. Original traces of diameter and intracellular calcium concentrations (ratio of fura-2 fluorescence with excitation at 340 and $380 \mathrm{~nm}$ ) of middle cerebral arteries (a) and coronary septal arteries (b) from CW and GK rats, as indicated. Transmural pressure was raised from 20 to 100 $\mathrm{mm} \mathrm{Hg}$ in 20 - $\mathrm{mm} \mathrm{Hg}$ increments, as indicated by black bars. Arteries from GK rats show less myogenic tone than CW arteries. Fura-2 $\mathrm{Ca}^{2+}$-dependent fluorescence is similar in both middle cerebral arteries and coronary septal arteries when comparing arteries from $\mathrm{CW}$ to $\mathrm{GK}$ rats.

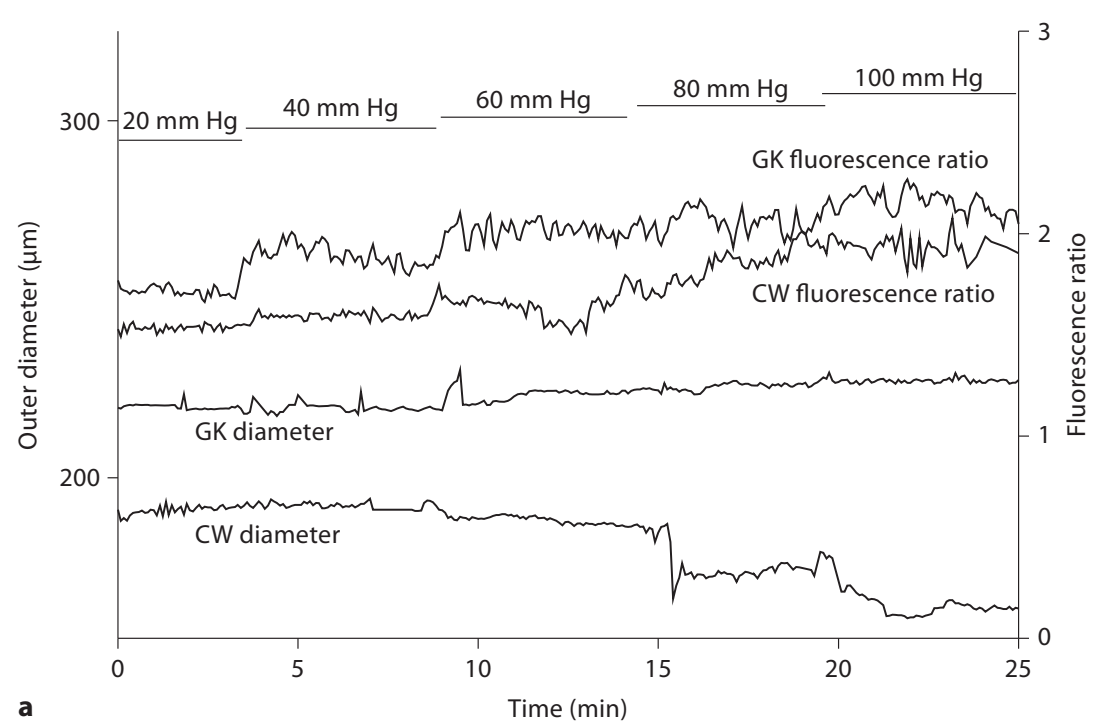

a

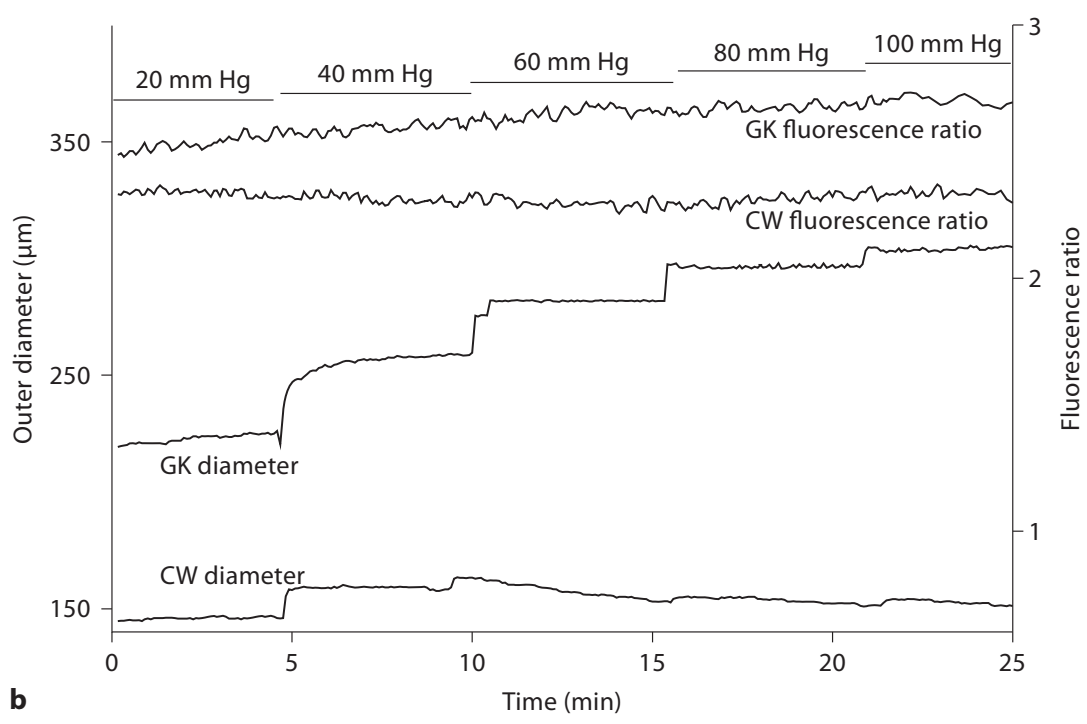

b
In 4 time control experiments with 3 repeated pressure-diameter curves no significant change in tone was seen, and repeating the U46619 concentration-response curve did not reveal any time-dependent change of response.

\section{Isobaric Diameter of Coronary Septal Arteries}

There was no difference in the average diameter of the coronary arteries at $100 \mathrm{~mm} \mathrm{Hg}$ in $\mathrm{Ca}^{2+}$-free conditions $(292 \pm 9$ vs. $272 \pm 11 \mu \mathrm{m}$, GK and CW rats, respectively, NS; $n=19,18$ ). In PSS, the myogenic tone was signifi- cantly lower in the coronary septal arteries from GK rats compared to arteries from $\mathrm{CW}$ rats $(\mathrm{p}<0.05 ; \mathrm{n}=7,8$; fig. $1 b, 2 b)$. This was also true after blocking of the NO synthesis as L-NAME had no significant effect on arteries from either GK or CW rats (fig. 3c). In the presence of the Rho-kinase inhibitors fasudil (fig. 3d) or Y-27632 (not shown) there was no difference in myogenic tone between arteries from GK and CW rats.

Increasing U46619 concentration at $60 \mathrm{~mm} \mathrm{Hg}$ increased the tone of the coronary arteries from both GK and CW rats (fig. $4 \mathrm{~b}$ ). The tones at the highest concen- 


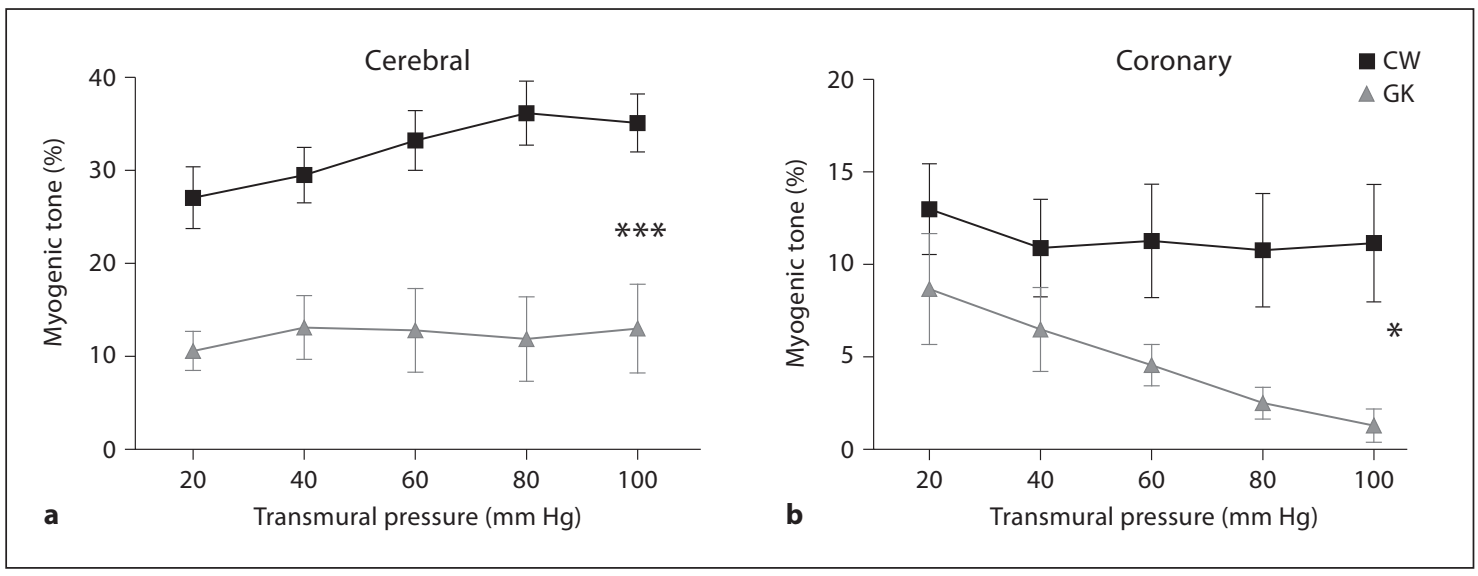

Fig. 2. Pressure-diameter curves of middle cerebral arteries (a) and septal coronary arteries (b) from CW and GK rats. $\mathrm{n}=5-12$; $^{*} \mathrm{p}<0.05$ and ${ }^{* * *} \mathrm{p}<0.001$, GK vs. CW (2-way ANOVA repeated measures).
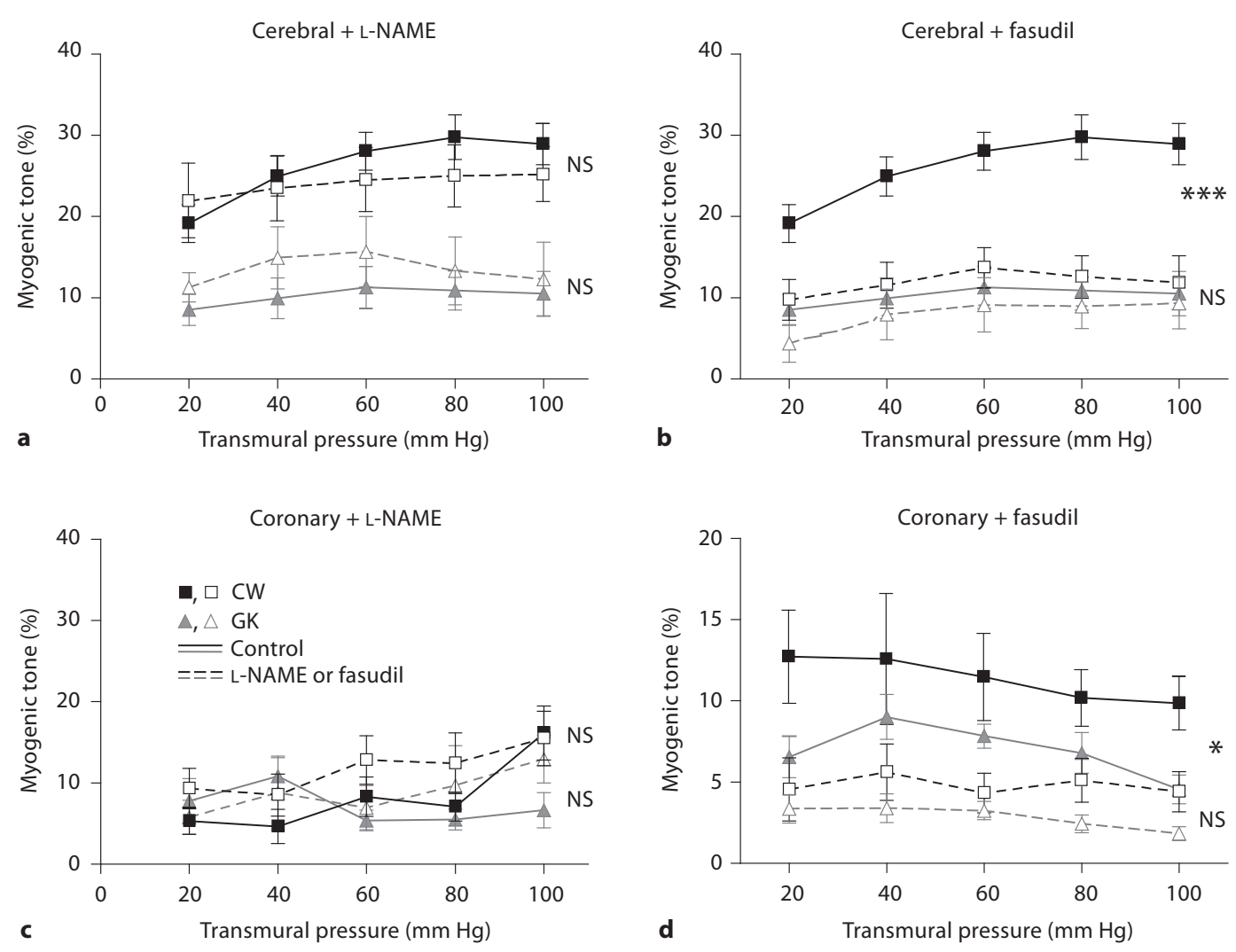

Fig. 3. Pressure-diameter curves of middle cerebral arteries $(\mathbf{a}, \mathbf{b})$ and septal coronary arteries (c, d) from CW and GK rats made under control conditions. a, c Effect of incubation with the L-NAME. $\mathbf{b}, \mathbf{d}$ Effect of incubation with fasudil. $\mathrm{n}=5-12 ;{ }^{*} \mathrm{p}<0.05$ and ${ }^{* * *} \mathrm{p}<0.0001$, treated vs. untreated (2-way ANOVA repeated measures).

Kold-Petersen/Brøndum/Nilsson/ Flyvbjerg/Aalkjaer 


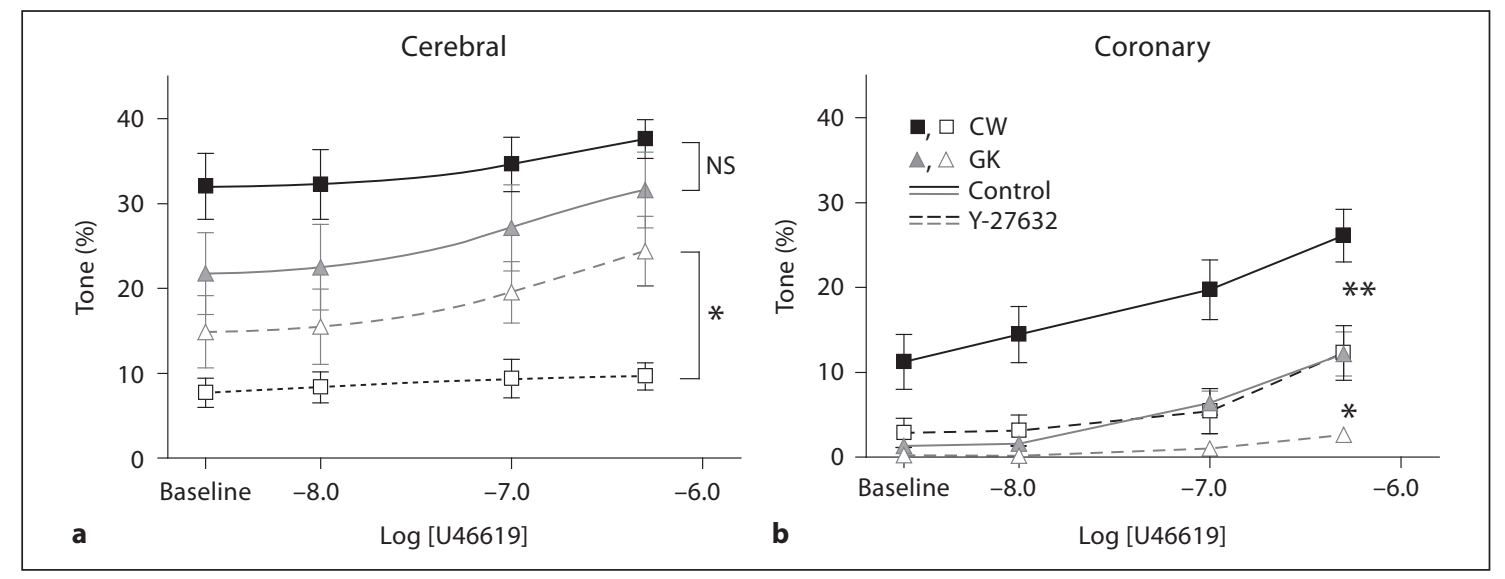

Fig. 4. Concentration response curves to U46619 in middle cerebral arteries (a) and septal coronary arteries (b) from CW and GK rats under control conditions and after incubation with the Rho-kinase inhibitor Y-27632. $\mathrm{n}=8-10 ;{ }^{*} \mathrm{p}<0.05$ and ${ }^{* *} \mathrm{p}<0.01$, GK vs. CW arteries (2-way ANOVA repeated measures).

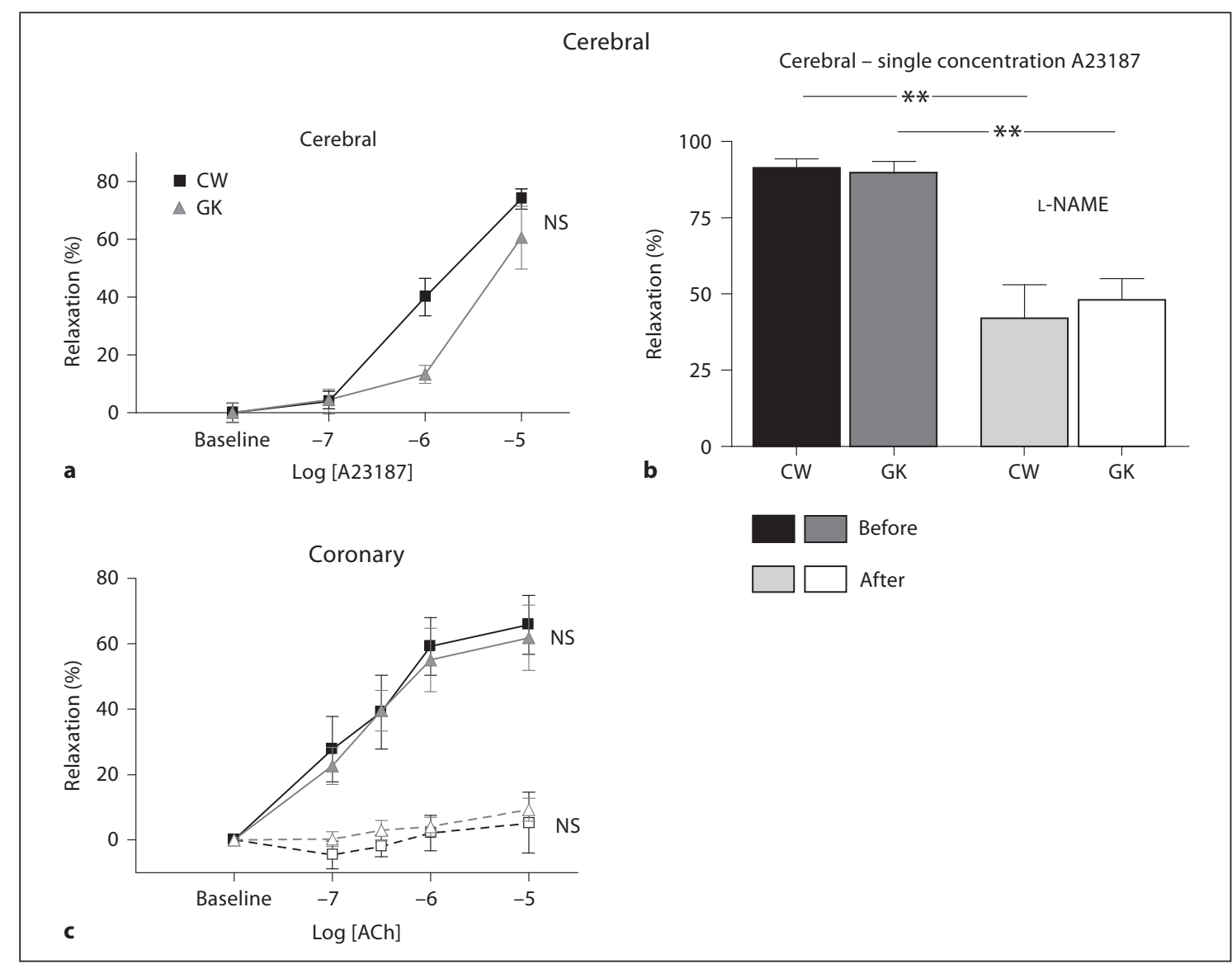

Fig. 5. Endothelium-mediated vasodilation in middle cerebral arteries (a, b) and coronary septal arteries (c). a The relaxation to cumulative concentrations of A23817 in middle cerebral arteries from CW and GK rats. b The relaxation of middle cerebral arteries to a single concentration $(10 \mu \mathrm{M})$ of A23187 before and after incubation with $100 \mu \mathrm{M}$ L-NAME. c The relaxation of coronary septal arteries to increasing concentrations of ACh in septal coronary arteries from CW and GK rats, before L-NAME and in the presence of L-NAME. $n=4-9$; ${ }^{* *} \mathrm{p}<0.001$, treated vs. untreated (Student's t test). 


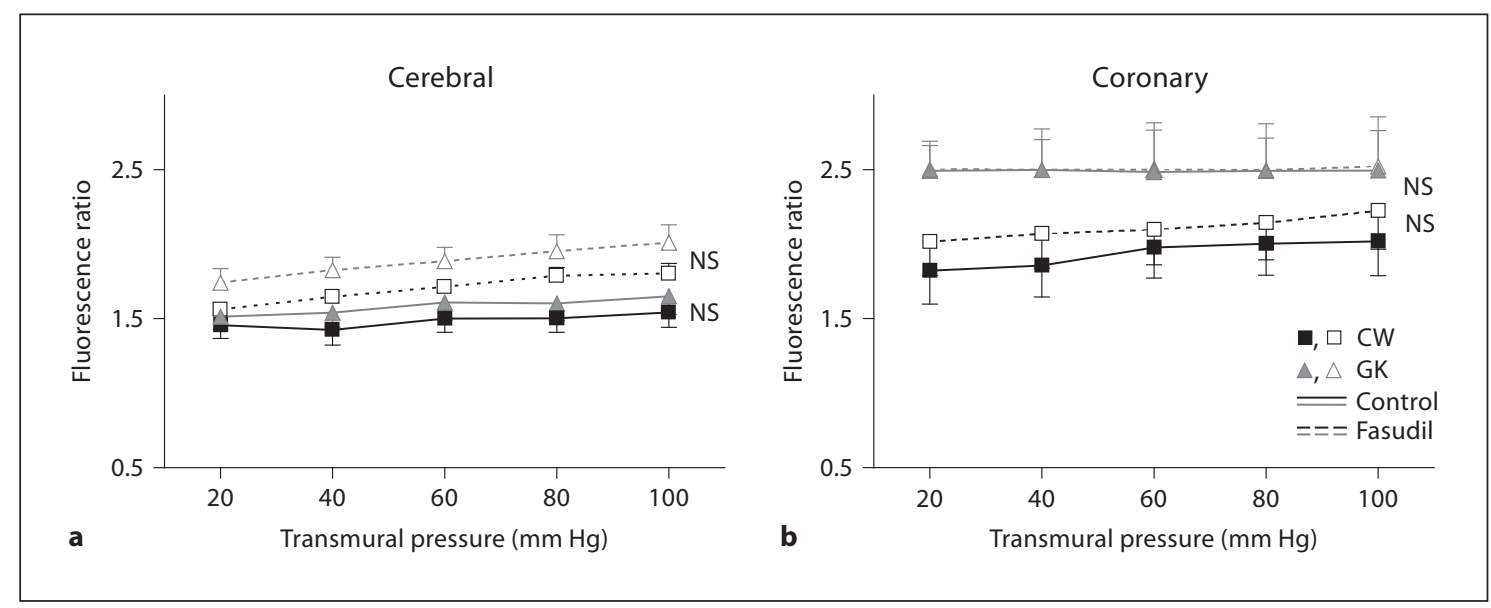

Fig. 6. Pressure-fluorescence ratio $\left[\mathrm{Ca}^{2+}\right]_{\mathrm{i}}$ curves of middle cerebral arteries (a) and coronary septal arteries (b) from $\mathrm{CW}$ rats and GK rats made under control conditions and after incubation with the Rho-kinase inhibitor fasudil. $\mathrm{n}=4-10$. GK vs. CW arteries (2-way ANOVA repeated measures).

tration of U46619 were $12 \pm 3$ and $26 \pm 3 \%(\mathrm{p}<0.05$; $\mathrm{n}=10,10)$, in GK and CW rats, respectively. Incubation with Y-27632 decreased the response in both groups, and the tones in the presence of the highest concentration of U46619 were $2.6 \pm 0.6$ and $12.2 \pm 3.2 \%(\mathrm{p}<$ $0.05 ; \mathrm{n}=10,10)$, in $\mathrm{GK}$ and $\mathrm{CW}$ rats, respectively, (fig. 4b).

Depolarization of the smooth muscle cells by 30 and $125 \mathrm{mM} \mathrm{K}^{+}$-PSS caused tone development and the tone during depolarization was similar in both groups (fig. 7). In a subset of animals endothelial function of the coronary arteries was investigated by obtaining cumulative concentration-response curves to ACh on arteries preconstricted with U46619. These curves showed no difference in the sensitivity or the maximal relaxing response ( $66 \pm 9$ vs. $62 \pm 10 \%$, in GK and CW rats, respectively, NS; $n=9$, 8; fig. 5 c). The ACh-mediated vasodilation was completely abolished in the presence of L-NAME (fig. 5c). In 3 experiments 2 consecutive relaxation curves to $\mathrm{ACh}$ on the same vessel without L-NAME were obtained. These time control experiments showed that ACh could elicit full relaxations both times. Despite the differences in tone between the two groups we observed no differences in $\left[\mathrm{Ca}^{2+}\right]_{i}$ over the entire pressure range (2-way ANOVA, NS) under control conditions, and after incubation with fasudil there were still no differences in $\left[\mathrm{Ca}^{2+}\right]_{\mathrm{i}}$ (fig. 1b, 6b), nor were there any differences in the absence of extracellular $\mathrm{Ca}^{2+}$ between the two groups in $\left[\mathrm{Ca}^{2+}\right]_{i}$ (fluorescence ratio $1.4 \pm 0.1$ vs. $1.2 \pm 0.2$ at $60 \mathrm{~mm} \mathrm{Hg}$, in GK and CW rats, respectively, NS; $n=9,10)$. Since

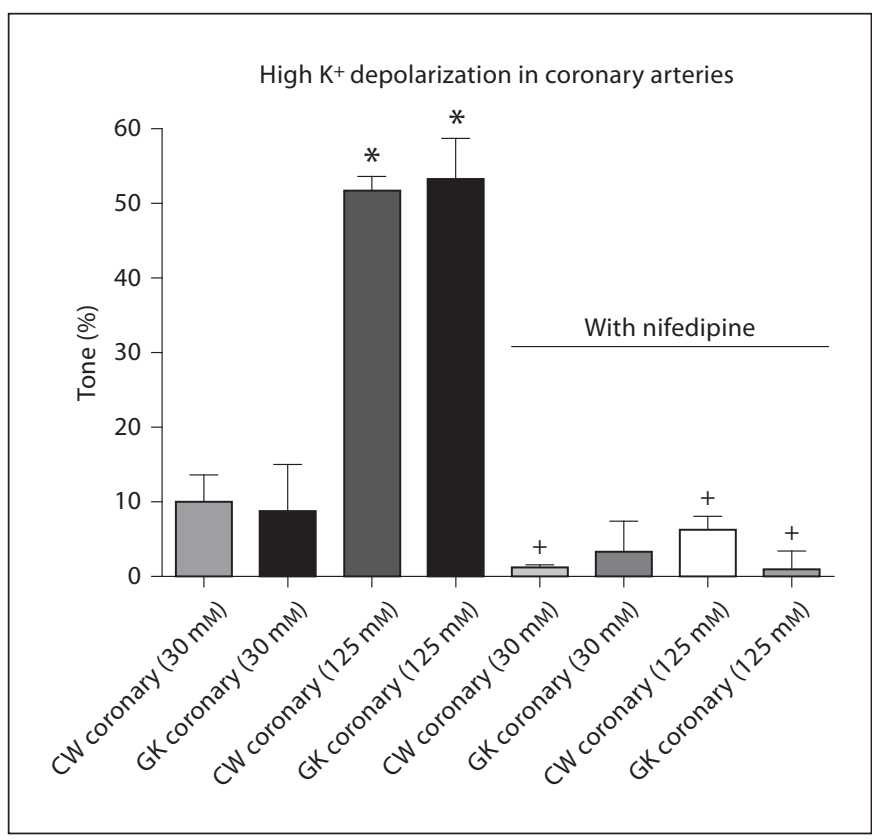

Fig. 7. Contraction of coronary arteries to $125 \mathrm{mM} \mathrm{K} \mathrm{K}^{+}$(K'-PSS) before and after inhibition with nifedipine. $\mathrm{n}=5 .{ }^{*} \mathrm{p}<0.001,30$ $\mathrm{mM} \mathrm{K} \mathrm{K}^{+}$-PSS vs. $125 \mathrm{mM} \mathrm{K}^{+}$-PSS.

there was little myogenic tone and no pressure-induced increase of $\left[\mathrm{Ca}^{2+}\right]_{\mathrm{i}}$ in the arteries, we measured the effect of the L-type $\mathrm{Ca}^{2+}$ channel blocker nifedipine on the contraction in arteries depolarized by 30 and $125 \mathrm{mM} \mathrm{K}^{+}$PSS. Nifedipine decreased the tone at both 30 and $125 \mathrm{mM}$ 
$\mathrm{K}^{+}$-PSS (fig. 7). In 4 time control experiments with 3 repeated pressure-diameter curves no significant change in tone was seen.

\section{Discussion}

The vascular abnormalities seen in diabetes are far from being fully characterized, possibly because they not only differ with the duration, severity and type of diabetes, but also may differ within the different vascular beds from the same individual $[23,24]$. The mechanism underlying diabetes-induced alterations of myogenic responses are also unclear. Some studies point towards a diabetesinduced increased myogenic tone, possibly via decreased responsiveness of the smooth muscle K-ATP-sensitive potassium channels [25], hyperglycemia-mediated activation of ET-1 and $\mathrm{ET}_{\mathrm{A}}$ receptors leading to vascular remodeling [26] or reduced endothelial function [27-29], while other studies point at reduced myogenic tone [30].

In the present study we found a reduced myogenic tone in isolated middle cerebral arteries and coronary septal arteries from the spontaneously diabetic GK rat, a model of nonobese T2D. The reduced myogenic tone seems to be caused by decreased $\mathrm{Ca}^{2+}$ sensitivity, probably due to a defective Rho-kinase pathway.

The vascular bed investigated is of key importance in cardiovascular pathology and is considered to be of importance for the consequences of microvascular angiopathies [1-3]. To ensure comparability we aimed at developing comparable protocols for the two vascular beds. However, as the cerebral arteries surprisingly did not respond to acetylcholine or bradykinin (unpubl. observation), A23187 was used as an endothelium-dependent vasodilator in these arteries. The 22-week-old rats used in this study were hyperglycemic but not hypertensive either at the age of 16 or 22 weeks. Chronic hypertension can therefore not explain the observed enlargement of the hearts. However, it is well established that GK rats develop features of diabetic cardiomyopathy [31], and this possibly explains the larger relative heart weight found in GK rats in this study.

The reduced myogenic tone in cerebral and coronary arteries from GK rats found in this study is in accordance with, and further extends, previous studies showing decreased myogenic tone in cerebral arteries from 18-weekold GK rats [17] and from human retinal and subcutaneous arteries [11,30], but contradicts results on cerebral arteries from rats with streptozotocin-induced diabetes showing increased myogenic tone [25]. As there was no difference in response between arteries (both cerebral and coronary) from GK and CW rats to full depolarization with $125 \mathrm{mM} \mathrm{K}^{+}$-PSS, it was apparent that the difference in development of myogenic tone was not due to a defective contractile apparatus.

We therefore investigated intracellular calcium and found similar fura-2 fluorescent ratios in response to increasing pressures in both the GK and CW rat vascular preparations. This suggests that the attenuation of myogenic tone is due to a decreased $\mathrm{Ca}^{2+}$ sensitivity. In the fura- 2 measurements the $\mathrm{R}_{\min }, \mathrm{R}_{\max }$ and the background signal were identical between the two groups of animals, supporting the theory that the fluorescence ratio is reflecting $\left[\mathrm{Ca}^{2+}\right]_{i}$ similarly in both groups. The data therefore strongly suggest that $\mathrm{Ca}^{2+}$ handling is not different in the arteries from the two groups.

To provide information on the background for the decreased $\mathrm{Ca}^{2+}$ sensitivity, which explained the decreased myogenic response, we used the Rho-kinase inhibitors Y-27632 and fasudil. Both compounds inhibit the phosphorylation of the myosin light chain, preventing the myosin cross-bridge to bind to the actin filaments and causing relaxation of the smooth muscle cells [32]. Y-27632 is considered a specific inhibitor of the Rho-kinase pathway [33], whereas fasudil is known to also affect the PKA and possibly the PKC pathways [34].

In the presence of the Rho-kinase inhibitors little myogenic tone was seen in either group and there was no difference between the groups. This suggests that a difference in Rho-kinase activity could explain the reduced $\mathrm{Ca}^{2+}$ sensitivity which underlies the reduced myogenic tone in both cerebral and coronary arteries, as previously shown for other diabetic animal models [35].

When stimulated with increasing concentrations of the vasoconstrictor U46619, both cerebral and coronary arteries showed a concentration-dependent increase in tone. In the cerebral arteries we did not observe a difference in tone to the highest concentration of U46619 used. Consistent with this, the tone in the presence of a supramaximal concentration of AVP was also similar between the groups. This suggests that in cerebral arteries agonistinduced responses are not different between arteries from GK and CW rats. However, this interpretation is complicated by the fact that the agonist-induced tone is developed on top of a myogenic tone which is different in the two groups.

The complexity of the agonist-induced responses was further underlined by the finding that cerebral arteries from GK rats developed more agonist-induced tone after inhibition of the Rho-kinase than the arteries from the 
CW rats. Although this finding is consistent with reduced signaling through the Rho-kinase pathway, it also suggests that a Rho-kinase-independent pathway for tone production is more prominent in cerebral arteries from GK rats compared to arteries from CW rats.

For the coronary arteries the situation was different. With the highest concentration of U46619 used the tone was significantly reduced in arteries from GK rats compared to arteries from CW rats both under control conditions and during Rho-kinase inhibition. This suggests the presence of a defect in the agonist-induced signaling in the coronary arteries which is not mediated by the Rho-kinase pathway. Possible candidates for these defects could include diabetes-induced alterations in the PKA [36] and the PKC [37, 38] pathways as recently shown for isolated glomeruli, but not for brain and liver microvessels, in 9-month-old GK rats [24]. These findings could possibly support our finding of similar agonist-induced responses in cerebral arteries from GK and CW rats.

The link between diabetes and increased activation of the PKC pathway is believed to involve the state of chronic hyperglycemia which leads to an increased level of circulating advanced glycation end products. The circulating advanced glycation end products bind to the endothelial-bound signal-transduction receptor RAGE, which in turn leads to activation of the smooth muscle cell PKC and thus oxidative stress $[39,40]$. It would therefore also be interesting in future studies to take into account the effects of glucose-induced PKC activation in hyperglycemic versus normoglycemic diabetes models [41].

The complexity of the vascular responses in the GK rats is further underlined by the observation that in mesenteric small arteries the myogenic tone was increased compared to mesenteric arteries from CW rats [26]. This finding was supported under isomeric conditions by our finding of an increased tension development in mesenteric small arteries from GK rats [24] and further stresses that the vascular dysfunction in diabetes may vary between different vascular beds. In this respect it is also interesting that Sandu et al. [42] found evidence of increased basal and thrombin-induced Rho-kinase activity in primary cultured smooth muscle cells from GK rat aortas and concluded that this would lead to enhanced vascular tone. This contrasts with the reduced tone seen in the present study and the evidence of a defective Rhokinase activity. Whether this difference is due to differences between the aorta and the cerebral and coronary resistance arteries or to the different experimental approaches is difficult to know.
The ACh concentration-dependent relaxation of coronary arteries and the A23187 concentration-dependent relaxation of cerebral arteries were almost complete and without differences between the CW and GK rat arteries. This suggests that no endothelial dysfunction was present in either of these vascular beds. This is in accordance with what we and others have previously shown in small mesenteric arteries [43] and aortic rings [32] from this rat model, although in the basilar artery from GK rats the ACh-induced isometric relaxation has been reported to be reduced [22]. The observation that the relaxation we report is inhibited by L-NAME indicates that the relaxation in the two vascular beds is dependent on the NO pathway, and that NO pathway is not impaired in either of the investigated vascular beds from the GK rat. Inhibition of NO production had no effect on either myogenic tone or $\left[\mathrm{Ca}^{2+}\right]_{\mathrm{i}}$ in the cerebral arteries or in the coronary septal arteries, indicating that $\mathrm{NO}$ has no explanatory potential in relation to the reduced myogenic tone in the GK rats. It is surprising that the inhibition of NO production did not affect myogenic tone in these arteries, as the presence of $\mathrm{NO}$ and constrictor prostaglandins have been shown to be essential for the normal development of the myogenic response in rat coronary arteries [44, 45]. However, since inhibition of NO production with LNAME did inhibit the agonist-induced endothelial-mediated relaxation, we believe that the lack of effect of LNAME on myogenic tone reflects a lack of NO-mediated contribution to myogenic tone.

The lack of endothelial dysfunction found in this study is somewhat surprising as diabetes is often associated with endothelial dysfunction, both in different animal models of T2D and in humans [30, 46-48]. One explanation may be that the GK rat is only moderately hyperglycemic when compared to other models of T2D, in particular as seen in models of obese T2D, e.g. the Zucker diabetic fatty rat [49-51]. Our findings that blood glucose was increased at the age of both 16 and 22 weeks indicate that at least in situations with mild chronic hyperglycemia the effect of NO is not altered. Also, our data suggest that mild hyperglycemia alone may not be sufficient to induce endothelial dysfunction, which has also been concluded by Bohlen and Lash [52] in the Zucker diabetic fatty rat, where there is no endothelial dysfunction present as long as hyperglycemia is associated with hyperinsulinemia.

In conclusion, in the GK rat model of lean T2D a decreased myogenic tone in cerebral and coronary resistance arteries occurs due to decreased calcium sensitivity. This is most likely explained by a defective Rho-kinase 
pathway. During agonist stimulation complex changes of signaling, which appear different in cerebral and coronary arteries, were present. It is of further interest that this model of diabetes appears without dysfunction of the endothelium-mediated NO-dependent relaxation despite hyperglycemia. These findings stress the complexity of the vascular dysfunction associated with diabetes.

\section{Acknowledgements}

This study was financially supported by the Danish Diabetes Association, the Danish Medical Research Council, the Eva and Henry Frænkels Memorial Foundation, the Institute of Clinical Medicine at Aarhus University, and the Danish National Research Council. The authors thank Kirsten Skaarup and Jørgen Andresen for excellent technical assistance.

\section{References}

1 Giorda CB, Avogaro A, Maggini M, Lombardo F, Mannucci E, Turco S, Alegiani SS, Raschetti R, Velussi M, Ferrannini E: Incidence and risk factors for stroke in type 2 diabetic patients: the DAI study. Stroke 2007; 38:1154-1160.

$\checkmark 2$ Wiernsperger N: Vascular defects in the aetiology of peripheral insulin resistance in diabetes. A critical review of hypotheses and facts. Diabetes Metab Rev 1994;10:287-307.

- 3 Nielsen H, Bonnema SJ, Flyvbjerg A: Effects of diabetes, insulin treatment, and osmolality on contractility of isolated rat resistance arteries. Pharmacol Toxicol 1995;77:209215.

4 Rayman G, Hassan A, Tooke JE: Blood flow in the skin of the foot related to posture in diabetes mellitus. Br Med J (Clin Res Ed) 1986;292:87-90.

5 Laight DW, Carrier MJ, Anggard EE: Endothelial cell dysfunction and the pathogenesis of diabetic macroangiopathy. Diabetes Metab Res Rev 1999;15:274-282.

6 Johnson PC: The myogenic response in the microcirculation and its interaction with other control systems. J Hypertens Suppl 1989;7:S33-S39.

7 Davis MJ: Myogenic response gradient in an arteriolar network. Am J Physiol 1993;264: H2168-H2179.

8 Meininger GA, Davis MJ: Cellular mechanisms involved in the vascular myogenic response. Am J Physiol 1992;263:H647-H659.

-9 Bayliss WM: On the local reactions of the arterial wall to changes of internal pressure. J Physiol 1902;28:220-231.

10 Greenstein AS, Price A, Sonoyama K, Paisley A, Khavandi K, Withers S, Shaw L, Paniagua O, Malik RA, Heagerty AM: Eutrophic remodeling of small arteries in type 1 diabetes mellitus is enabled by metabolic control: a 10 -year follow-up study. Hypertension 2009; 54:134-141.

11 Lorenzi M, Feke GT, Pitler L, Berisha F, Kolodjaschna J, McMeel JW: Defective myogenic response to posture change in retinal vessels of well-controlled type 1 diabetic patients with no retinopathy. Invest Ophthalmol Vis Sci 2010;51:6770-6775.
12 Davis MJ, et al (eds): Local Regulation of Microvascular Perfusion. Academic Press, 2008.

13 Uehata M, Ishizaki T, Satoh H, Ono T, Kawahara T, Morishita T, Tamakawa H, Yamagami K, Inui J, Maekawa M, Narumiya S: Calcium sensitization of smooth muscle mediated by a Rho-associated protein kinase in hypertension. Nature 1997;389:990-994.

14 Ishizaki T, Uehata M, Tamechika I, Keel J, Nonomura K, Maekawa M, Narumiya S: Pharmacological properties of Y-27632, a specific inhibitor of Rho-associated kinases. Mol Pharmacol 2000;57:976-983.

15 Rikitake Y, Kim HH, Huang Z, Seto M, Yano K, Asano T, Moskowitz MA, Liao JK: Inhibition of Rho kinase (ROCK) leads to increased cerebral blood flow and stroke protection. Stroke 2005;36:2251-2257.

16 Goto Y, Kakizaki M, Masaki N: Production of spontaneous diabetic rats by repetition of selective breeding. Tohoku J Exp Med 1976; 119:85-90

17 Kelly-Cobbs A, Elgebaly MM, Li W, Ergul A: Pressure-independent cerebrovascular remodelling and changes in myogenic reactivity in diabetic Goto-Kakizaki rat in response to glycaemic control. Acta Physiol (Oxf) 2010;203:245-251.

18 Janssen U, Vassiliadou A, Riley SG, Phillips AO, Floege J: The quest for a model of type II diabetes with nephropathy: the Goto Kakizaki rat. J Nephrol 2004;17:769-773.

19 Witte K, Jacke K, Stahrenberg R, Arlt G, Reitenbach I, Schilling L, Lemmer B: Dysfunction of soluble guanylyl cyclase in aorta and kidney of Goto-Kakizaki rats: influence of age and diabetic state. Nitric Oxide 2002;6: $85-95$.

20 Witte K, Reitenbach I, Stolpe K, Schilling L, Kirchengast M, Lemmer B: Effects of the endothelin A receptor antagonist darusentan on blood pressure and vascular contractility in type 2 diabetic Goto-Kakizaki rats. J Cardiovasc Pharmacol 2003;41:890-896.

21 Brondum E, Nilsson H, Aalkjaer C: Functional abnormalities in isolated arteries from Goto-Kakizaki and streptozotocin-treated diabetic rat models. Horm Metab Res 2005; 37(suppl 1):56-60.
22 Harris AK, Hutchinson JR, Sachidanandam K, Johnson MH, Dorrance AM, Stepp DW, Fagan SC, Ergul A: Type 2 diabetes causes remodeling of cerebrovasculature via differential regulation of matrix metalloproteinases and collagen synthesis: role of endothelin-1. Diabetes 2005;54:2638-2644.

23 Ivey ME, Osman N, Little PJ: Endothelin-1 signalling in vascular smooth muscle: pathways controlling cellular functions associated with atherosclerosis. Atherosclerosis 2008;199:237-247.

-24 Wang H, Jiang YW, Zhang WJ, Xu SQ, Liu HL, Yang WY, Lou JN: Differential activations of PKC/PKA related to microvasculopathy in diabetic GK rats. Am J Physiol Endocrinol Metab 2012;302:E173-E182.

25 Zimmermann PA, Knot HJ, Stevenson AS, Nelson MT: Increased myogenic tone and diminished responsiveness to ATP-sensitive $\mathrm{K}^{+}$channel openers in cerebral arteries from diabetic rats. Circ Res 1997;81:996-1004.

26 Sachidanandam K, Hutchinson JR, Elgebaly MM, Mezzetti EM, Dorrance AM, Motamed K, Ergul A: Glycemic control prevents microvascular remodeling and increased tone in type 2 diabetes: link to endothelin-1. Am J Physiol Regul Integr Comp Physiol 2009; 296:R952-R959.

27 Kobayashi T, Kamata K: Effect of insulin treatment on smooth muscle contractility and endothelium-dependent relaxation in rat aortae from established STZ-induced diabetes. Br J Pharmacol 1999;127:835-842.

28 Matsumoto T, Kobayashi T, Kamata K: Alterations in EDHF-type relaxation and phosphodiesterase activity in mesenteric arteries from diabetic rats. Am J Physiol Heart Circ Physiol 2003;285:H283-H291.

29 Matsumoto T, Wakabayashi K, Kobayashi T, Kamata K: Alterations in vascular endothelial function in the aorta and mesenteric artery in type II diabetic rats. Can J Physiol Pharmacol 2004;82:175-182.

- 30 Schofield I, Malik R, Izzard A, Austin C, Heagerty A: Vascular structural and functional changes in type 2 diabetes mellitus: evidence for the roles of abnormal myogenic responsiveness and dyslipidemia. Circulation 2002;106:3037-3043. 
-31 El-Omar MM, Yang ZK, Phillips AO, Shah AM: Cardiac dysfunction in the Goto-Kakizaki rat. A model of type II diabetes mellitus. Basic Res Cardiol 2004;99:133-141.

-32 Rosen P, Wiernsperger NF: Metformin delays the manifestation of diabetes and vascular dysfunction in Goto-Kakizaki rats by reduction of mitochondrial oxidative stress. Diabetes Metab Res Rev 2006;22:323-330.

33 Davies SP, Reddy H, Caivano M, Cohen P: Specificity and mechanism of action of some commonly used protein kinase inhibitors. Biochem J 2000;351:95-105.

-34 Sachidanandam K, Harris A, Hutchinson J, Ergul A: Microvascular versus macrovascular dysfunction in type 2 diabetes: differences in contractile responses to endothelin-1. Exp Biol Med 2006;231:1016-1021.

-35 Didion SP, Lynch CM, Baumbach GL, Faraci FM: Impaired endothelium-dependent responses and enhanced influence of Rho-kinase in cerebral arterioles in type II diabetes. Stroke 2005;36:342-347.

-36 Doyle ME, Egan JM: Mechanisms of action of glucagon-like peptide 1 in the pancreas. Pharmacol Ther 2007;113:546-593.

37 Idris I, Gray S, Donnelly R: Protein kinase C activation: isozyme-specific effects on metabolism and cardiovascular complications in diabetes. Diabetologia 2001;44:659-673.

38 Massett MP, Ungvari Z, Csiszar A, Kaley G, Koller A: Different roles of PKC and MAP kinases in arteriolar constrictions to pressure and agonists. Am J Physiol Heart Circ Physiol 2002;283:H2282-H2287.
39 Thallas-Bonke V, Thorpe SR, Coughlan MT, Fukami K, Yap FY, Sourris KC, Penfold SA, Bach LA, Cooper ME, Forbes JM: Inhibition of NADPH oxidase prevents advanced glycation end product-mediated damage in diabetic nephropathy through a protein kinase C-alpha-dependent pathway. Diabetes 2008; 57:460-469.

40 Ungvari Z, Pacher P, Kecskemeti V, Papp G, Szollar L, Koller A: Increased myogenic tone in skeletal muscle arterioles of diabetic rats. Possible role of increased activity of smooth muscle $\mathrm{Ca} 2^{+}$channels and protein kinase $\mathrm{C}$. Cardiovasc Res 1999;43:1018-1028.

41 Amadio M, Bucolo C, Leggio GM, Drago F, Govoni S, Pascale A: The PKCbeta/HuR/ VEGF pathway in diabetic retinopathy. Biochem Pharmacol 2010;80:1230-1237.

42 Sandu OA, Ragolia L, Begum N: Diabetes in the Goto-Kakizaki rat is accompanied by impaired insulin-mediated myosin-bound phosphatase activation and vascular smooth muscle cell relaxation. Diabetes 2000;49: 2178-2189.

43 Brondum E, Kold-Petersen H, Nilsson H, Flyvbjerg A, Aalkjaer C: Increased contractility to noradrenaline and normal endothelial function in mesenteric small arteries from the Goto-Kakizaki rat model of type 2 diabetes. J Physiol Sci 2008;58:333-339.

44 Szekeres M, Nadasy GL, Kaley G, Koller A: Nitric oxide and prostaglandins modulate pressure-induced myogenic responses of intramural coronary arterioles. J Cardiovasc Pharmacol 2004;43:242-249.

45 Bagi Z, Koller A, Kaley G: Superoxide-NO interaction decreases flow- and agonist-induced dilations of coronary arterioles in Type 2 diabetes mellitus. Am J Physiol Heart Circ Physiol 2003;285:H1404-H1410.
46 De Vriese AS, Verbeuren TJ, Van de Voorde, Lameire NH, Vanhoutte PM: Endothelial dysfunction in diabetes. Br J Pharmacol 2000;130:963-974.

47 Rizzoni D, Porteri E, Guelfi D, Muiesan ML, Piccoli A, Valentini U, Cimino A, Girelli A, Salvetti M, De Ciuceis C, Tiberio GA, Giulini SM, Sleiman I, Monteduro C, Rosei EA: Endothelial dysfunction in small resistance arteries of patients with non-insulin-dependent diabetes mellitus. J Hypertens 2001;19: 913-919.

48 Rizzoni D, Rosei EA: Small artery remodeling in diabetes mellitus. Nutr Metab Cardiovasc Dis 2009; 19:587-592.

49 Brondum E, Kold-Petersen H, Simonsen U, Aalkjaer C: NS309 restores EDHF-type relaxation in mesenteric small arteries from type 2 diabetic ZDF rats. Br J Pharmacol 2010;159:154-165.

50 Oltman CL, Richou LL, Davidson EP Coppey LJ, Lund DD, Yorek MA: Progression of coronary and mesenteric vascular dysfunction in Zucker obese and Zucker diabetic fatty rats. Am J Physiol Heart Circ Physiol 2006;291:H1780-H1787.

51 Peterson RG, Shaw WN, Neel M, Little LA, Eichberg J: Zucker diabetic fatty rat as a model for non-insulin-dependent diabetes mellitus. ILAR J 1990;32:16-19.

52 Bohlen HG, Lash JM: Endothelial-dependent vasodilation is preserved in non-insulin-dependent Zucker fatty diabetic rats. Am J Physiol 1995;268:H2366-H2374. 